\title{
Reforms in General English Teaching in Vocational Higher Education Based on the Student Diversity ---Take Solely-enrolled Students for Example
}

\author{
Luo Dongshan \\ Wuhan Railway Vocational College of Technology, Wuhan China
}

Keywords: student diversity; solely-enrolled students; General English teaching situations; causes;

\section{solutions}

Abstract. Solely-enrolled students are the typical representative of the admissions from various sources to higher vocational colleges. The investigation shows that the English learning situations of solely-enrolled students are quite dissatisfactory. And they don't do well in such aspects as learning attitude, self-control, learning autonomy, learning approaches etc. This paper analyzes the causes, and discusses the solutions.

\section{Introduction}

In recent years, with China's higher vocational education examination enrollment system reformed, the sources of admissions to higher vocational colleges have shown a trend of variety and diversity. Owing to the various sources, students differ from each other in learning foundation and abilities, and they are very weak in basic theory, which bring much difficulty to teaching. The difficulty in teaching can be obviously shown in basic cultural courses, especially in General English. Higher vocational colleges must actively respond to the challenge.

As the typical representative of the admissions from various sources to higher vocational colleges, solely-enrolled students from secondary vocational schools (commonly known as solely-enrolled students, the same below) are a special group in higher vocational colleges. Their characteristics lie in the three aspects as follows:

Firstly, the exam they take is very special, the subjects of which are determined by the college they decide to enter. And exams are written by the college, which marks papers too.

Secondly, the exam contents are very special, which are composed of basic cultural courses + skills operation + interview, aiming at highlighting such solely-enrolled students' skills more than their basic cultural knowledge, and exploring their potentials. Although such students are weak in basic cultural courses, they have their superiorities, e.g. having mastered lots of skills and being skilled in operating. However, at present, many secondary vocational schools pay more attention to skills and operating than cultural knowledge and theories. And the curricula of higher vocational colleges tend to be arranged upon the consideration of the basic cultural knowledge, professional theory, professional skills, etc. of the students coming from senior high schools, without considering the characteristics of solely-enrolled students. As a result, they have great difficulty in learning, which is clearly shown in General English [1] - [3].

The education administrative departments and the researchers in the fields have expressed their great concern about the difficulty in learning for solely-enrolled students. The document Opinions on How to Deepen the Teaching Reform of Vocational Education to Comprehensively Improve the Quality of Talent Cultivation by the Ministry of Education of P.R.C. (the Vocational Education \& Adult Education Department of the Ministry of Education , [2015] No. 6) clearly points out that it' $\mathrm{s}$ vital to promote the connection between secondary and higher vocational education and to actively advance the linkage of talent cultivation between them, of which the course linkage is the most important[4] - [6]. 
It $s$ very inevitable to make an investigation into the English teaching situations of solely-enrolled students in order to ensure the effective linkage of English teaching between secondary and higher vocational education, and the speedy adaptation of solely-enrolled students to General English teaching of higher vocational colleges.

Based on the above analysis, the author took the following measures: firstly, gaining lots of advice about the teaching reform of General English by interviewing solely-enrolled students, the English teachers in a higher vocational college, secondary vocational school English teachers, and the enterprises related to the majors of the college where the author works; secondly, on the basis of the combination of literature research, open questionnaire, classroom observation, individual interviews, etc, designing a questionnaire, the content of which involves basic English knowledge, learning methods, learning habits, teaching contents, and teaching methods; thirdly, using the method of cluster sampling, surveying 95 solely-enrolled freshmen of a higher vocational college at the same time and at the same place, and getting 90 effective copies of the questionnaire with the copies which were not completely answered taken out; finally, doing the frequency analysis of the questionnaire data by using SPSS17.0 for Windows.

\section{Analysis of the English teaching situations}

Analysis of the survey result. The data analysis of the questionnaire shows that as a whole, the English teaching situations of solely-enrolled students are quite dissatisfactory. $43.4 \%$ of the students have no interest in English learning, and are unwilling to learn it, either. $42.2 \%$ of the students can only communicate with others in easy English, and they don' $t$ think they have any confidence in learning English well. 11.1\% of the students think they have mastered the basic grammar and language skills. Surprisingly, only 3.3\% of the students think they have much confidence in English and that they can fluently communicate with others in English.

A further analysis of the questionnaire results shows that such students don' $t$ do well in such aspects as learning attitude, self-control, learning autonomy, learning approaches etc. In terms of learning attitude, a few of them have the habit of thinking carefully and actively participate in the classroom activities. By contrast, most of them are passively involved in the classroom activities and usually respond to teachers' questions using "I can' $t$ " or “I don' $t$ know" . It' $s$ very common for them to copy assignments. And what' s more, they don' $t$ think highly of their learning attitude with a proportion of $64.5 \%$. It' $\mathrm{s}$ also very common for such students to skip classes in an explicit or tacit way, reaching a proportion of 5.6\% and $60.0 \%$ respectively, which means they don' t have very good self-control ability. Solely-enrolled students don' t have strong learning initiative, and only $1.1 \%$ of them use websites, or electronic lesson plans to learn autonomously. In addition, only $11.1 \%$ of them are willing to prepare before class and revise after class. And students are rarely seen to learn together, only $16.7 \%$ of whom do so. As a result, $71.1 \%$ of them need to be pushed to learn, which shows that their consciousness of autonomous learning needs to be urgently enhanced. As for learning approaches, $65.6 \%$ of them don' $t$ have very good methods to learn because they have no clear objectives or strong learning motivation.

Causes of dissatisfactory English learning situations. The English learning situations of solely-enrolled students are quite dissatisfactory. By using literature research and interviewing secondary vocational school English teachers, the English teachers in a higher vocational college and solely-enrolled students, the author finds that in general, the dissatisfactory situations result from the following reasons:

To begin with, such students are weak in the basic language knowledge so that they have no passion for English learning or self-confidence in it. Students in secondary vocational schools, most of whom failed in the Entrance Examination for Senior High Schools, have very bad English foundation. They have no interest in English learning, and their learning initiative is poor, too. A Study on the Requirements of the Secondary Vocational Education on Students ' Cultural Knowledge Level and Learning Competence, the specialized research subject of vocational education 
of the Ministry of Education, carried out in 2007, showed that in terms of the English course, 38.63\% of the students in secondary vocational schools did not master what primary school graduates should do, and $72.24 \%$ of them did not master what students in the second year of junior middle school should do, while only $9.62 \%$ of them reached the higher level of excellence in English.[7]

Next, secondary vocational schools don' t attach great importance to the English course. In such schools, with the curricula often based on the employment-oriented principle, professional courses, practical training courses, and practice courses account for a higher percentage, while the English course does a lower percentage. Therefore, such curricula have had a bad effect on secondary vocational school students' attitude to English learning to such an extent that they think it's useless to learn English, and that it' s no matter that they don' t learn English.

In the third place, as for English teaching, secondary vocational schools have no fixed or unified teaching plans, which to a certain degree reflect the randomness of the teaching arrangement.

Lastly, secondary vocational schools lack effective communication with higher vocational colleges in talent cultivation objectives, teaching contents etc, which badly affects the linkage of the English courses.

(1) Higher vocational colleges don' t have the same talent cultivation objectives as secondary vocational schools, which makes it difficult for the English courses to achieve effective linkage.

(2) The integrality of the English curriculum contents of secondary vocational schools as well as the incompatibility with the subsequent higher vocational college General English leads to much difficulty in the linkage of the English courses. Secondary vocational English teaching contents are divided into basic module, professional module and extended module. Because of the integrality of the content system, the division of the curriculum is beneficial to cultivating students' basic knowledge, professional ability, and cultural quality simultaneously. General English in higher vocational colleges

emphasizes basic language knowledge and the infiltration of culture in teaching. However, its teaching contents don' thave much to do with students' majors and future career.

(3) Most of the teaching materials of higher vocational college General English are quite similar to those of secondary vocational school English course with much language training repeated, so it is difficult to arouse solely-enrolled students' interest in English learning.

\section{Solutions}

(1)The formulation of a proper teaching syllabus

Solely-enrolled students are hard to be motivated, and their learning ability is limited. Besides, they lack self-management consciousness. As a result, when formulating the teaching syllabus for higher vocational college General English, English teachers should consider such factors as its pertinence, its professional features, and its innovative features. On the basis of the above thinking, it' $s$ very necessary for higher vocational colleges to formulate a classified school-based teaching syllabus suited to solely-enrolled students for General English.

(2)The choice of employment-oriented teaching contents

Higher vocational college General English teaching should be based on service, and meet the needs of students and their potential positions, so the teaching contents, which are not only suitable for solely-enrolled students but also helpful in the linkage of the English courses, should be chosen on the basis of needs analysis to fully learn about the needs of solely-enrolled students. Of course, the employment-oriented teaching contents, helpful in the linkage of English courses, should be suitable for professional requirements as well as the needs of language teaching, and at the same time, the contents should satisfy the interests of solely-enrolled students. In addition, English teachers should choose teaching materials together with specialized course teachers.

(3)The optimization of classroom teaching environment

The classroom is the main place for teaching activities, and the efficiency of the classroom teaching depends on the coordination of teachers, students and teaching environment with each other. 
And teaching environment is an essential prerequisite for teaching activities, and badly affects the teaching result. Literature research shows good, suitable classroom teaching environment can improve students' learning efficiency and teaching quality, and the classroom psychological environment, in particular, has an significant impact on the teaching result [8] - [11].The survey the author did also shows that solely-enrolled students hope higher vocational college English teachers can build an equal, harmonious and relaxing classroom atmosphere, and that they should be the center of the classroom teaching. They wish their English teachers to meet their requirements, and to attend to them. In the meanwhile, they hope their teachers can be close to them willingly. They think that if their teachers take all the above measures, they can build up much confidence in General English and their teachers.

Optimizing the classroom teaching psychological environment is one of the effective ways to improve the teaching quality of higher vocational college General English. The optimization of the classroom teaching psychological environment of General English can be done through English teachers' focusing on emotional teaching, strengthening the training of learning strategies and solely-enrolled students' transformation of learning approaches. Therefore, such students can engage themselves in General English classroom teaching in a positive state of mind and good learning behavior so that the teaching quality of General English can be greatly improved.

(4)The innovation of teaching approaches

Solely-enrolled students have a very poor foundation in English, and what' s more, they lack interest in English learning. Therefore, General English teachers in higher vocational colleges must innovate on teaching approaches. In terms of the innovation of teaching approaches, the principles involve inheritance and promotion so that traditional teaching approaches and innovative ones can be well combined with each other. On the one hand, English teachers should guide students to what they haven' t mastered so that they can consolidate their language foundation, and effectively take advantage of modern information teaching tools to activate classroom atmosphere, and to relieve students' anxiety. Thus, the teaching efficiency can be improved. And on the other hand, English teachers themselves should be active in the classroom activities, helping students to determine topics, to design contexts, and to decompose tasks so that a cooperation class can be formed. In this way can students' team spirit be cultivated. Furthermore, English teachers should try to make the classroom extended and encourage students to make full use of various online learning resources so that their ability of autonomous learning can be cultivated.

(5)The establishment of the evaluation system with a diversity of evaluation contents and a multivariate of evaluation subjects

Considering the specific circumstances of solely-enrolled students, the development of students and the improvement of the classroom teaching efficiency can be achieved through the establishment of the evaluation system with a diversity of evaluation contents and a multivariate of evaluation subjects. Specifically speaking, in terms of evaluation contents, such elements as preparation before class, class contributions (discussion in class, role-playing, group activities, workplace simulations, presentations, etc), autonomous learning (online learning, making electronic products, etc.), encouragement to peer students and learning results should be included in the evaluation system used to evaluate students' comprehensive application ability of English. The evaluation subjects should be composed of the English teacher, the commissary in charge of studies, the class representative of the English course, students themselves, group leaders, etc. The class representative of the English course plays a very important part in the achievement evaluation. The percentage of evaluation contents should be determined by the evaluation subjects.

\section{References}

[1] Bu Aihui, Qu Jing, Li Xiaoyan. Present English Learning Situations of Self-enrolling Higher Vocational College Students \& Analysis of Teaching Reform [ J ] . Journal of Xingtai Polytechnic College, 2012, (2): 8〜10. 
[2] Zhang Qiang. On the Teaching Reform of Vocational College General English for Solely-enrolled Students [J]. Overseas English, 2014, (8): 79 80.

[3] Wei Zhengzhu. English Learning Situations of Vocational College Solely-enrolled Students: Analysis of the Investigation \& Countermeasures $[\mathrm{J}]$. Journal of Xianning University, 2012, (1): $130 \sim 131$.

[4] Gao Ming. A Review of the Research on the Course Linkage between Secondary Vocational Schools and Higher Vocational Colleges in China: 2000-2013 - Based on the Analysis of Cnki.Net Literature $[\mathrm{J}]$. Vocational \& Technical Education Forum, 2014, (33): 17 21.

[5] Zhao Zhiqun. The Enlightenment of Overseas Course Linkage between Secondary Vocational Schools and Higher Vocational Colleges $[\mathrm{J}]$. Vocational \& Technical Education Forum, 2002, (22): $62 \sim 64$.

[6] Lu Jingchang. Thinking of the Linkage between Secondary Vocational Schools and Higher Vocational Colleges $[\mathrm{J}]$. Chinese Vocational and Technical Education, 2005, (7): 18 19 .

[7] Jiang Naiping. Cultural Courses Should Make Secondary Vocational School Students "Well Done-One of the Reports from the Teaching Forefront $[\mathrm{J}]$. Chinese Vocational and Technical Education, 2008, (14): 11 15.

[8] Cheng Hualin. Optimum Strategies of Classroom Teaching Psychological Environment in Higher Vocational English Teaching $[\mathrm{J}]$. Journal of Baotou Vocational \&Technical College,2008,(3 ): 53 55.

[9] Zhang Mei. On How to Establish an Active Classroom Psychological Environment [J] . Vocational Education Research, 2009, (12): 90 92.

[10] Yu Kaihui. Enhancing Teaching and Learning Quality of College English by Optimizing Classroom Teaching Psychological Environment $[\mathrm{J}]$. Journal of Guangxi Normal University for Nationalities, 2012, (1): 121 123.

[11] Hua La, Bao Cuilian. A Questionnaire Survey on the Ecological Environment of English Classroom in Vocational Colleges in Inner Mongolia $[\mathrm{J}]$. Research on Higher Education of Nationalities, 2015, (1): 72 75. 